J. Electroanal. Chem., 227 (1987) 183-198

Elsevier Sequoia S.A., Lausanne - Printed in The Netherlands

\title{
KINETICS AND MECHANISM OF H AND OH ELECTROSORPTION ON FACETED (100) Pt ELECTRODES IN ACID SOLUTIONS
}

\author{
S.A. BILMES, M.C. GIORDANO and A.J. ARVIA \\ Instituto de Investigaciones Fisicoquimicas Teóricas y Aplicadas (INIFTA) ${ }^{\star}$, C.C. 16, Sucursal 4, \\ (1900) La Plata (Argentina)
}

(Received 14th April 1986; in revised form 14th November 1986)

\begin{abstract}
The multiplicity of voltammetric peaks related to $\mathrm{H}$-adatom and $\mathrm{OH}$ electroadsorption/electrodesorption reactions on faceted (100) $\mathrm{Pt}$ in $1 \mathrm{M} \mathrm{H}_{2} \mathrm{SO}_{4}$ and $0.5 \mathrm{M} \mathrm{HClO}_{4}$ are investigated at different temperatures by using linear sweep voltammetry with triangular modulation covering a relatively large frequency range of the modulating signal. The voltammetric multiplicity related to $\mathrm{H}$-adatom reactions in acid electrolytes is sensitive to both the surface structure and the structure of the solution side of the edl. The kinetics of the reactions are apparently influenced in a cooperative way by the water-H-adatom-anion ensemble formed at each site of a particular crystallographic plane. The main three reactions exhibit different relaxation time constants from which one can infer that the process occurring in the potential range presumably closer to the potential of zero charge is the slowest one. Anion adsorption produces a surface energy leveling effect and changes the kinetics of the electrochemical reactions.

The $\mathrm{H}$-adatom reactions can be interpreted through a formalism comprising the surface diffusion of $\mathrm{H}$-adatom among different adsorption sites followed by a relatively fast electrochemical step involving only one kind of $\mathbf{H}$-adatom.

Data obtained for the OH-adsorbed reaction show, in principle, the same trend as that of the $\mathrm{H}$-adatom reactions, although in this respect more extensive data are required.
\end{abstract}

\section{INTRODUCTION}

The voltammetric characteristics of polycrystalline (pc) Pt electrodes can be modified drastically by applying a fast periodic potential program in acid electrolytes during a certain time [1,2]. Depending on the preset conditions for the periodic potential, a particular electrochemical faceting can be developed, as can be seen through scanning electron microscopy $[3,4]$ and well-characterized to the nanometer range through ex-situ scanning tunneling microscopy observations [5]. With regard to surface crystallography and type of defects at room temperature, scanning

\footnotetext{
* Facultad de Ciencias Exactas, Universidad Nacional de La Plata, Argentina.
} 
tunneling microscopy imaging of preferred oriented (100) platinum surfaces is similar to that of $\mathrm{Pt}(100)$ single crystals [6]. This is presumably the reason why a faceted (100) Pt electrode obtained through electrochemical faceting acquires the voltammetric response which has been reported for a Pt (100) single crystal electrode, including two different stabilized voltammograms at low sweep rates $(<0.1 \mathrm{~V} / \mathrm{s})$ depending on whether the anodic switching potential is lower or higher than the threshold potential for irreversible $O$ electroadsorption [7]. The two types of stabilized electrodes were denoted as HASE (hydrogen adsorption stabilised faceted (100) Pt electrodes), and OASE (oxygen adsorption stabilised faceted (100) Pt electrode), the voltammetric response of these electrodes being influenced by the electrolyte composition and temperature [7].

The present paper refers to the application of triangular modulated triangular sweep voltammetry (TMTSV) to the study of the kinetics and mechanism of the various pairs of reversible current peaks associated with the udp of water on faceted (100) Pt electrodes in acid solutions at different temperatures. TMTSV was found to be a suitable technique for studying fast pseudo-capacitive electrode processes when proper time windows and small modulated amplitudes are used [8-10]. The kinetic behaviour of both $\mathrm{H}$-adatom and $\mathrm{OH}$ electrosorption processes is examined and a plausible mechanism for $\mathrm{H}$-adatom electrosorption involving a multiplicity of adsorption sites is advanced. The corresponding data are compared with those reported in the literature and discussed in terms of a probable dynamic structure of the electrode/solution interface [11-13].

\section{EXPERIMENTAL}

Runs were made in a two-compartment Pyrex glass cell of about $50 \mathrm{ml}$ capacity provided with a glass jacket for thermostatic liquid circulation. The design and distribution of the working electrode, counterelectrode and reference electrode assured a homogeneous current distribution and a negligible distortion of the potential signal applied to the working electrode. This was tested by inserting a $\mathrm{Pt}$ probe parallel to the Luggin capillary tip and the working electrode. The probe was connected to the reference electrode through a variable capacitor, $C(1 \mu \mathrm{F} \leqslant C \leqslant 14$ $\mu F)$. No distortion of the electrical response of the system was observed in the frequency range used in the present work. Both the working electrode and the counterelectrode were made from Pt wires $(0.5 \mathrm{~mm}$ diameter, Johnson Matthey Chem. Co., spectroscopically pure). A reversible hydrogen electrode (RHE) in $1 M$ $\mathrm{H}_{2} \mathrm{SO}_{4}$ was used as reference. $1 \mathrm{M} \mathrm{H}_{2} \mathrm{SO}_{4}$ and $0.5 M \mathrm{HClO}_{4}$ were prepared from purified water (Milli $\mathrm{Q}^{\#}$ ), 98\% $\mathrm{H}_{2} \mathrm{SO}_{4}$ (Merck p.a.), and $70 \% \mathrm{HClO}_{4}$ (Merck Suprapure), respectively. Water satisfied the purity requirements usually accepted for electrocatalysis [14]. Experiments were made either in the $-2.5^{\circ} \mathrm{C}$ to $25^{\circ} \mathrm{C}$ range $\left(0.5 \mathrm{M} \mathrm{HClO}_{4}\right)$ or in the $-3.5^{\circ} \mathrm{C}$ to $46^{\circ} \mathrm{C}$ range $\left(1 \mathrm{M} \mathrm{H}_{2} \mathrm{SO}_{4}\right)$.

The faceted (100) Pt working electrodes were prepared from polycrystalline (pc) Pt wires $\left(0.02 \mathrm{~cm}^{2}\right.$ apparent area) following the procedure described elsewhere [7]. The roughness factor of these electrodes as estimated from the $\mathbf{H}$-adatom voltam- 
metric charge at $0.1 \mathrm{~V} / \mathrm{s}$, with the monolayer charge equal to $210 \mu \mathrm{C} / \mathrm{cm}^{2}$, was between 1.1 and 1.3.

TMTSV was used by setting the guide ramp sweep rate $\left(v_{\mathrm{g}}\right)$ at $1 \mathrm{~V} / \mathrm{s}$, the triangular modulating signal sweep rate $\left(v_{\mathrm{m}}\right)$ in the $20 \mathrm{~V} / \mathrm{s}$ to $1200 \mathrm{~V} / \mathrm{s}$ range, and the amplitude of the modulating signal $\left(A_{\mathrm{m}}\right)$ in the $26 \mathrm{mV}$ to $100 \mathrm{mV}$ range. The ratio $A_{\mathrm{m}} / v_{\mathrm{m}}$ determines the characteristic time of the modulating signal $\left(t_{\mathrm{m}}\right)$ and the corresponding frequency is $f_{\mathrm{m}}=1 / 2 t_{\mathrm{m}}$.

The experimental setup consisted of a Tacussel function generator (GSATP) and a fast LYP ramp coupled to the potentiostat (Tacussel PIT 20-2X). The rise time of the potentiostat was comprised between 0.1 and $0.2 \mu \mathrm{s}$ and that of the electrolytic cell assembly was 8-20 $\mu$ s. The complex current-potential profiles (TMTPS voltammograms) resulting from TMTSV were taken from the oscilloscope screen. Further details about the TMTSV technique are given in refs. 8-10.

TMTSV was applied in the positive potential direction under the following, different working conditions: (i) by starting from a faceted (100) Pt electrode stabilized by potential cycling at $0.1 \mathrm{~V} / \mathrm{s}$ in the $0.03-0.60 \mathrm{~V}$ range, i.e. in the potential range of $\mathrm{H}$-adatom electrosorption/electrodesorption (HASE): (ii) by extending the anodic switching potential up to $1.4 \mathrm{~V}$ and by recording the first TMTSV to gain information about the initial stages of $O$ electroadsorption; (iii) by recording the stabilized TMTSV for a (100) Pt electrode which had been TMTSVcycled for $3 \mathrm{~min}$ in the $0.03-1.4 \mathrm{~V}$ range (OASE).

\section{RESULTS}

\section{Triangular modulated triangular sweep voltammetry data}

TMTSV resulting for a $\mathrm{HASE}$ in $1 \mathrm{M} \mathrm{H}_{2} \mathrm{SO}_{4}$, at $25^{\circ} \mathrm{C}$, at different $A_{\mathrm{m}}$ and $v_{\mathrm{m}}$, shows three pairs of conjugated current peaks described earlier [7], $A_{I} / C_{I}, A_{I I} / C_{I I}$ and $\mathrm{A}_{\mathrm{III}} / \mathrm{C}_{\mathrm{III}}$ (Fig. 1a, b). The anodic to cathodic charge ratio from the entire current-potential profile becomes independent of frequency at constant $A_{\mathrm{m}}$ and remains practically equal to unity during potential cycling, including the stabilization stage. Otherwise, the $\mathrm{H}$-adatom voltammetric charge decreases, although in a selective way, as the modulating frequency, $f_{\mathrm{m}}$, increases, but the charge contribution of peak $A_{1} / C_{I}$ decreases faster than those associated with peaks $A_{I I I} / C_{I I I}$ and $A_{I I} / C_{I I}$. These results suggest that the rate of the electrochemical reaction related to peaks $A_{I I} / C_{I I}$ and $A_{I I I} / C_{I I I}$ is greater than that corresponding to peaks $A_{I} / C_{I}$. In the potential range of these reactions the slope of each current-time response of the modulating cycle approaches $90^{\circ}$ for the smallest $A_{\mathrm{m}}$ values (Figs. 1 and 3).

Similar experiments carried out in $0.5 \mathrm{M} \mathrm{HClO}_{4}$ (Fig. 1c) show remarkable differences as compared to those run in $1 \mathrm{M} \mathrm{H}_{2} \mathrm{SO}_{4}$, as was expected from previous results [7]. In $0.5 M \mathrm{HClO}_{4}$ peaks $\mathrm{A}_{\mathrm{II}} / \mathrm{C}_{\mathrm{II}}$ are practically negligible and peaks $\mathrm{A}_{1} / \mathrm{C}_{1}$ become broader than in $1 \mathrm{M} \mathrm{H}_{2} \mathrm{SO}_{4}$. In addition, a reversible current hump is evident in the potential range of the electrical double layer (edl). The voltammetric charge for $\mathrm{H}$-adatoms is $35 \%$ smaller in $0.5 \mathrm{M} \mathrm{HClO}$ than in $1 \mathrm{M} \mathrm{H}_{2} \mathrm{SO}_{4}$ under comparable experimental conditions. These voltammetric differences can be attri- 




Fig. 1. TMTPS voltammograms of a HASE faceted (100) Pt electrode at $25^{\circ} \mathrm{C}$ in $1 \mathrm{M} \mathrm{H}_{2} \mathrm{SO}_{4}$ (a and b) and in $0.5 \mathrm{MHClO}_{4}$ (c). $v_{\mathrm{g}}=1 \mathrm{~V} / \mathrm{s}$. (a): $v_{\mathrm{m}}=80 \mathrm{~V} / \mathrm{s}, A_{\mathrm{m}}=26 \mathrm{mV} ;\left(\mathrm{b}\right.$ and c): $v_{\mathrm{m}}=60 \mathrm{~V} / \mathrm{s}$. $A_{\mathrm{m}}=60$ mV. 


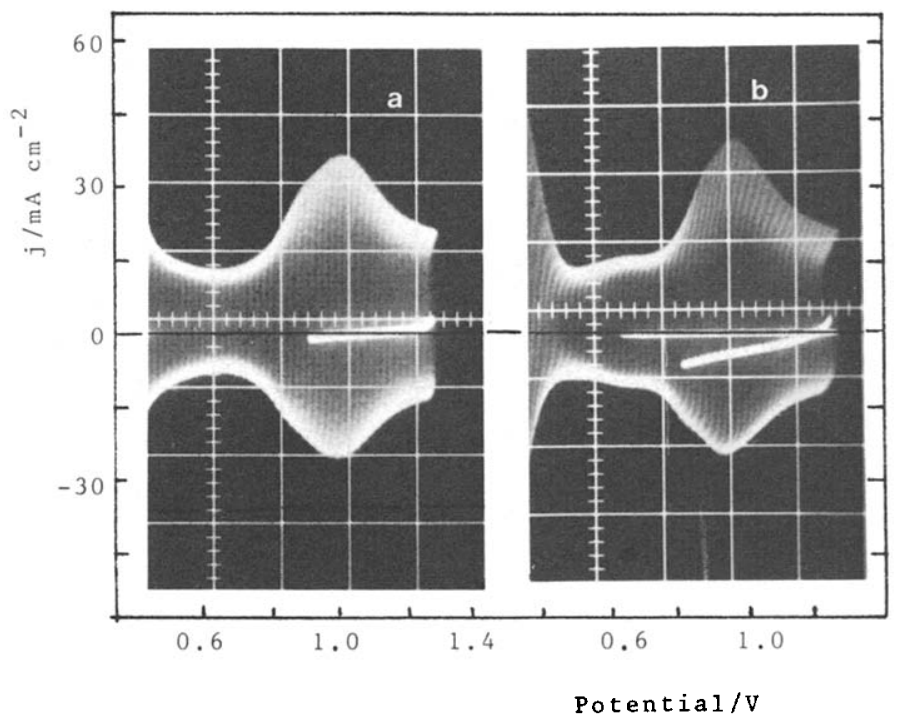

Fig. 2. TMTPS voltammograms (1st scan) of faceted (100) Pt electrodes at $25^{\circ} \mathrm{C}$ run to $E_{\mathrm{s}, \mathrm{a}}>0.8 \mathrm{~V}$ (procedure ii). $v_{\mathrm{g}}=1 \mathrm{~V} / \mathrm{s}$. (a) $1 \mathrm{M} \mathrm{H}_{2} \mathrm{SO}_{4}, v_{\mathrm{m}}=80 \mathrm{~V} / \mathrm{s}, A_{\mathrm{m}}=26 \mathrm{mV}$; (b) $0.5 M \mathrm{HClO}_{4}, v_{\mathrm{m}}=60 \mathrm{~V} / \mathrm{s}$, $A_{\mathrm{m}}=60 \mathrm{mV}$.

buted to the particular influence of anions on the kinetics of $\mathbf{H}$-adatom electroadsorption/electrodesorption.

The first TMTSV run with faceted (100) Pt electrodes subjected to condition (ii) (Fig. 2a, b) shows a broad complex reversible pair of peaks at ca. $0.9 \mathrm{~V}$ assigned to $\mathrm{OH}$ electroadsorption/electrodesorption. These peaks are broader in $1 \mathrm{M} \mathrm{H}_{2} \mathrm{SO}_{4}$ than in $0.5 \mathrm{M} \mathrm{HClO}_{4}$. For the latter the peak is preceded by a reversible current hump in the edl region $(0.6-0.7 \mathrm{~V})$ (Fig. 1c). This result correlates with the relatively large and potential-dependent voltammetric current recorded in the edl region for pc $\mathrm{Pt}$ electrodes in $\mathrm{HClO}_{4}$ solutions at $0.1 \mathrm{~V} / \mathrm{s}$ [15].

Different TMTSV results are obtained for OASE resulting under condition (iii), depending on whether the electrolyte is $1 \mathrm{M} \mathrm{H}_{2} \mathrm{SO}_{4}$ or $0.5 \mathrm{M} \mathrm{HClO}_{4}$ (Fig. 3). The charge evaluated from peaks $\mathrm{A}_{\mathrm{I}} / \mathrm{C}_{\mathrm{I}}$ is smaller, and the charge contribution of peaks $\mathrm{A}_{\mathrm{III}} / \mathrm{C}_{\mathrm{III}}$ is higher in $0.5 \mathrm{M} \mathrm{HClO}_{4}$ than in $1 \mathrm{M} \mathrm{H}_{2} \mathrm{SO}_{4}$. In addition, two reversible couples are observed in the $0.9-1.1 \mathrm{~V}$ range, namely peak $\mathrm{O}_{\mathrm{I}}$ at ca. $0.9 \mathrm{~V}$ and peak $\mathrm{O}_{\mathrm{II}}$ at ca. $1.05 \mathrm{~V}$, which indicates that $\mathrm{OH}$ electroadsorption/electrodesorption also involves two distinguishable stages. Furthermore, the splitting of the $\mathrm{OH}$ electroadsorption/electrodesorption peaks, becomes clearer in $0.5 \mathrm{M} \mathrm{HClO}_{4}$ than in $1 \mathrm{M}$ $\mathrm{H}_{2} \mathrm{SO}_{4}$. However, there is a lack of definition of $\mathrm{OH}$ electroadsorption/electrodesorption peaks in $0.5 \mathrm{M} \mathrm{HClO}_{4}$ for $t_{\mathrm{m}}<8 \times 10^{-5} \mathrm{~s}$. The reversible double peak for the $\mathrm{OH}$ electroadsorption/electrodesorption apparently turns out the voltammetric fingerprint for OASE in both $1 \mathrm{M} \mathrm{H}_{2} \mathrm{SO}_{4}$ and $0.5 \mathrm{M} \mathrm{HClO}_{4}$. The potential difference between the anodic and cathodic current maxima for both 


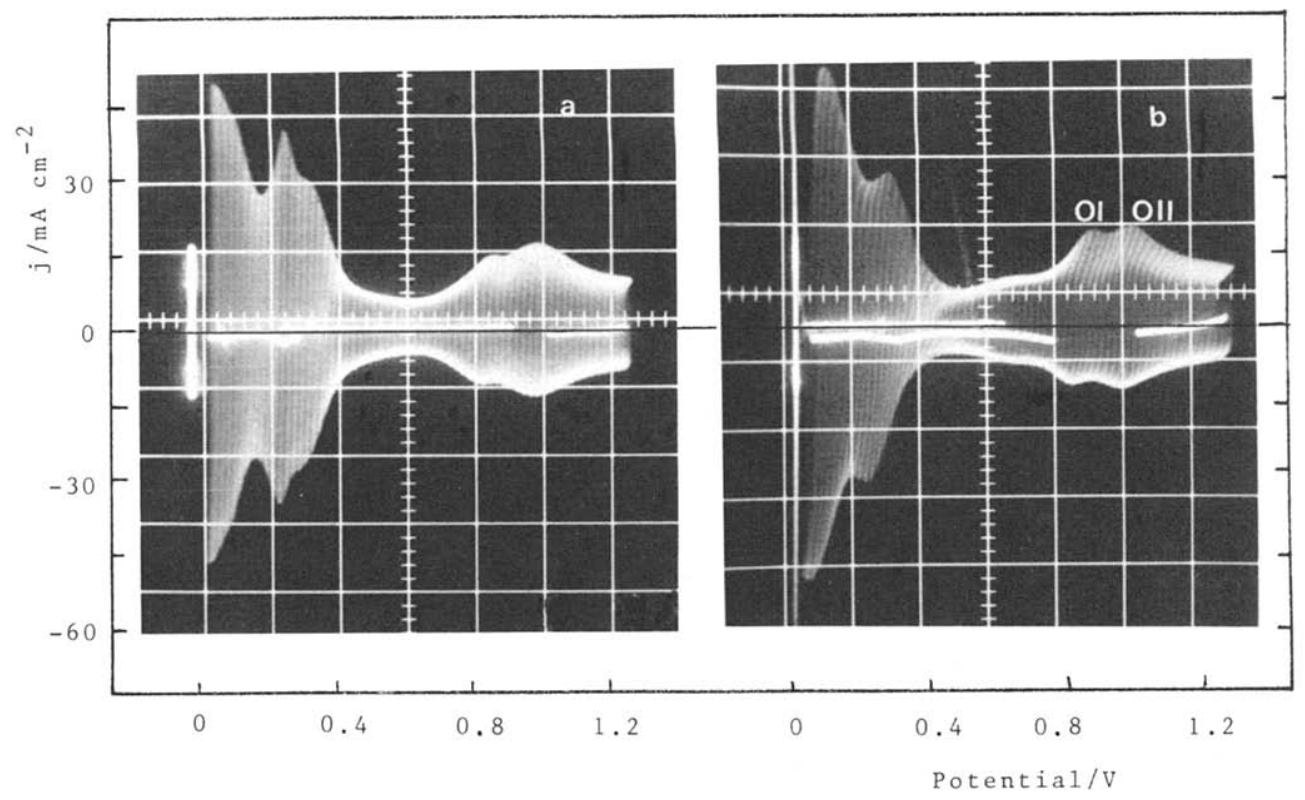

Fig. 3. TMTPS voltammograms for an OASE-faceted (100) Pt electrode at $25^{\circ} \mathrm{C}$ (procedure iii). (a) $1 \mathrm{M}$ $\mathrm{H}_{2} \mathrm{SO}_{4}$; (b) $0.5 \mathrm{M} \mathrm{HClO}_{4}$. TMTPS parameters are the same as indicated in Fig. 2.

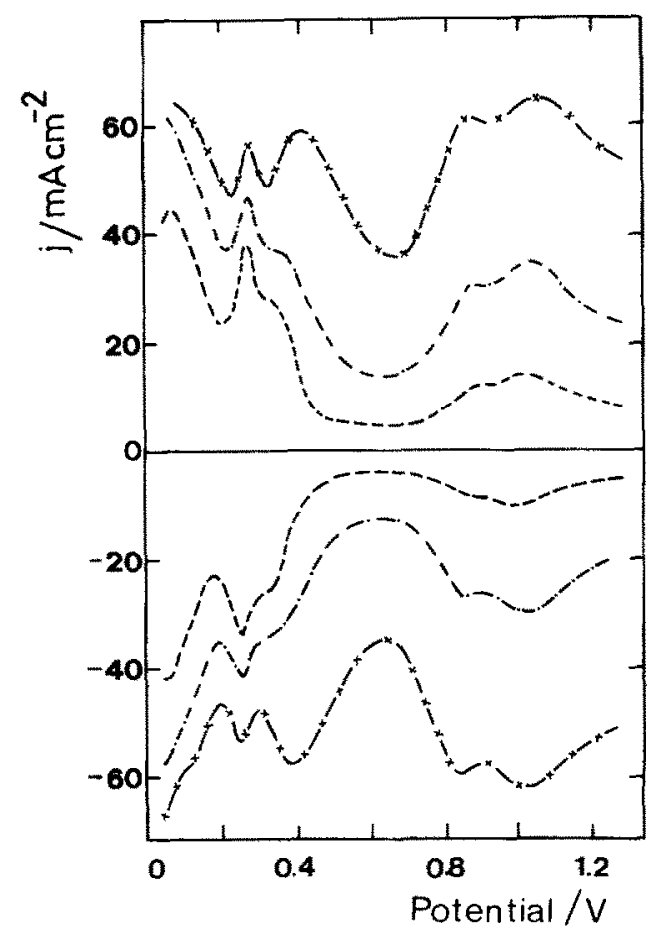

Fig. 4. TMTPS contours for OASE-faceted (100) Pt electrodes at different $v_{\mathrm{m}}$ and $25^{\circ} \mathrm{C}$ in $1 \mathrm{M} \mathrm{H}_{2} \mathrm{SO}_{4}$. $v_{\mathrm{g}}=1 \mathrm{~V} / \mathrm{s} . A_{\mathrm{m}}=26 \mathrm{mV}, v_{\mathrm{m}}=60 \mathrm{~V} / \mathrm{s}(--,) ; 200 \mathrm{~V} / \mathrm{s}(\cdot-\cdot-\cdot) ; 600 \mathrm{~V} / \mathrm{s}(\times \longrightarrow \times)$. 
$\mathrm{H}$-adatom and $\mathrm{OH}$ electroadsorption/electrodesorption followed through the TMTSV is practically independent of $v_{\mathrm{m}}$ in the whole range of $t_{\mathrm{m}}$ (Fig. 4). The apparent shift of peak potential for peak $A_{I I}$ with $v_{m}$ is not really observed after deconvolution. Similar results are obtained from $\mathrm{OH}$ electroadsorption/electrodesorption for $t_{\mathrm{m}}<2 \times 10^{-4} \mathrm{~s}$, whereas the anodic to cathodic area ratio in the $0.9-1.3 \mathrm{~V}$ range increases according to $t_{\mathrm{m}}$ for $t_{\mathrm{m}}>2 \times 10^{-4} \mathrm{~s}$.

\section{Influence of temperature in the TMTSV}

Decreasing the temperature produces a decrease in the overall TMTSV charge associated with $\mathrm{H}$-adatom electrodesorption/electrodesorption for any faceted (100) $\mathrm{Pt}$ electrode independently of the previous conditions in both $1 \mathrm{M} \mathrm{H}_{2} \mathrm{SO}_{4}$ (Fig. 5) and $0.5 \mathrm{M} \mathrm{HClO}_{4}$ (Fig. 6). Comparatively, smaller changes in the $\mathrm{OH}$ electroadsorption/electrodesorption charge with temperature are observed.

The temperature dependence of peaks $A_{I}, A_{I I}$ and $A_{I I I}$ can be analyzed independently through the pseudo-capacitance, $C_{\mathrm{s}}$, at the current peak $I_{\mathrm{M}}\left(C_{\mathrm{s}}=I_{\mathrm{M}} / v_{\mathrm{m}}\right)$ in both electrolytes for two extreme $v_{\mathrm{m}}$ values (Fig. 7). Peak overlapping was resolved by graphical deconvolution, by extrapolating the main peak $A_{I}$ with a Gaussian function and further subtraction from the overall curve. The same procedure was adopted for peak $\mathbf{A}_{\text {III }}$ at low temperature, which also exhibits a splitting. In this case only the most positive peak $A_{\text {III }}$ was considered for calculation. It should be noticed, however, that both peaks have a similar height. For peak $\mathrm{A}_{\mathrm{I}}, C_{\mathrm{s}}$ increases linearly with temperature in both electrolytes although the temperature coefficient in $1 \mathrm{M} \mathrm{H}_{2} \mathrm{SO}_{4}$ is greater than in $0.5 \mathrm{M} \mathrm{HClO}_{4}$ at $v_{\mathrm{m}}=60 \mathrm{~V} / \mathrm{s}$. The opposite temperature effect is noticed on the height of peak $A_{\text {III }}$. For the latter, a non-linear temperature dependence is observed. Peak $A_{I I}$, at low temperature, approaches the temperature dependence of peak $\mathrm{A}_{\mathrm{I}}$, whereas beyond $20^{\circ} \mathrm{C}$ it reaches a constant value. On the other hand, the temperature coefficient of peak $\mathrm{A}_{\mathrm{I}}$ in $1 M \mathrm{H}_{2} \mathrm{SO}_{4}$ for $v_{\mathrm{m}}=600 \mathrm{~V} / \mathrm{s}$ is substantially smaller than that for $v_{\mathrm{m}}=60 \mathrm{~V} / \mathrm{s}$. Peaks $\mathrm{A}_{\mathrm{I}}, \mathrm{A}_{\mathrm{II}}$ and $\mathrm{A}_{\mathrm{III}}$ at $600 \mathrm{~V} / \mathrm{s}$ exhibit linear nearly parallel $C_{\mathrm{s}}$ vs. $T$ plots.

Peaks $\mathrm{A}_{\mathrm{III}} / \mathrm{C}_{\mathrm{III}}$ exhibit a splitting in $1 \mathrm{M} \mathrm{H}_{2} \mathrm{SO}_{4}$ at the lowest temperature (Fig. 5) which is similar to that reported previously in dilute $\mathrm{H}_{2} \mathrm{SO}_{4}$ at low sweep rates [16]. Neither peak $A_{\text {II }}$ nor the splitting of peak $A_{\text {III }}$ is observed at low temperatures in $0.5 \mathrm{M} \mathrm{HClO}_{4}$ (Fig. 6).

These results indicate the simultaneous influence of the faceted (100) Pt surface and the electrolyte composition on the overall $\mathrm{H}$-adatom reactions, although the reactions associated with peaks $A_{I} / C_{I}$ are apparently more sensitive to the structure of the electrode surface than to the electrolyte composition as compared to peaks $A_{I I} / C_{I I}$.

\section{Dependence of $C_{s}$ on modulating frequency at constant temperature}

The different processes observed in the entire range for water underpotential decomposition at the electrode can be followed through the dependence of $C_{\mathrm{s}}$ on either $f_{\mathrm{m}}$ or $t_{\mathrm{m}} \cdot C_{\mathrm{s}}$ vs. $t_{\mathrm{m}}$ relationships for the pair of peaks $\mathrm{A}_{\mathrm{I}} / \mathrm{C}_{\mathrm{I}}, \mathrm{A}_{\mathrm{II}} / \mathrm{C}_{\mathrm{II}}$ and $\mathrm{A}_{\mathrm{III}} / \mathrm{C}_{\mathrm{III}}$ for a HASE in $1 \mathrm{M}^{\mathrm{H}} \mathrm{H}_{2} \mathrm{SO}_{4}$ are shown in Fig. 8. Similar plots were 


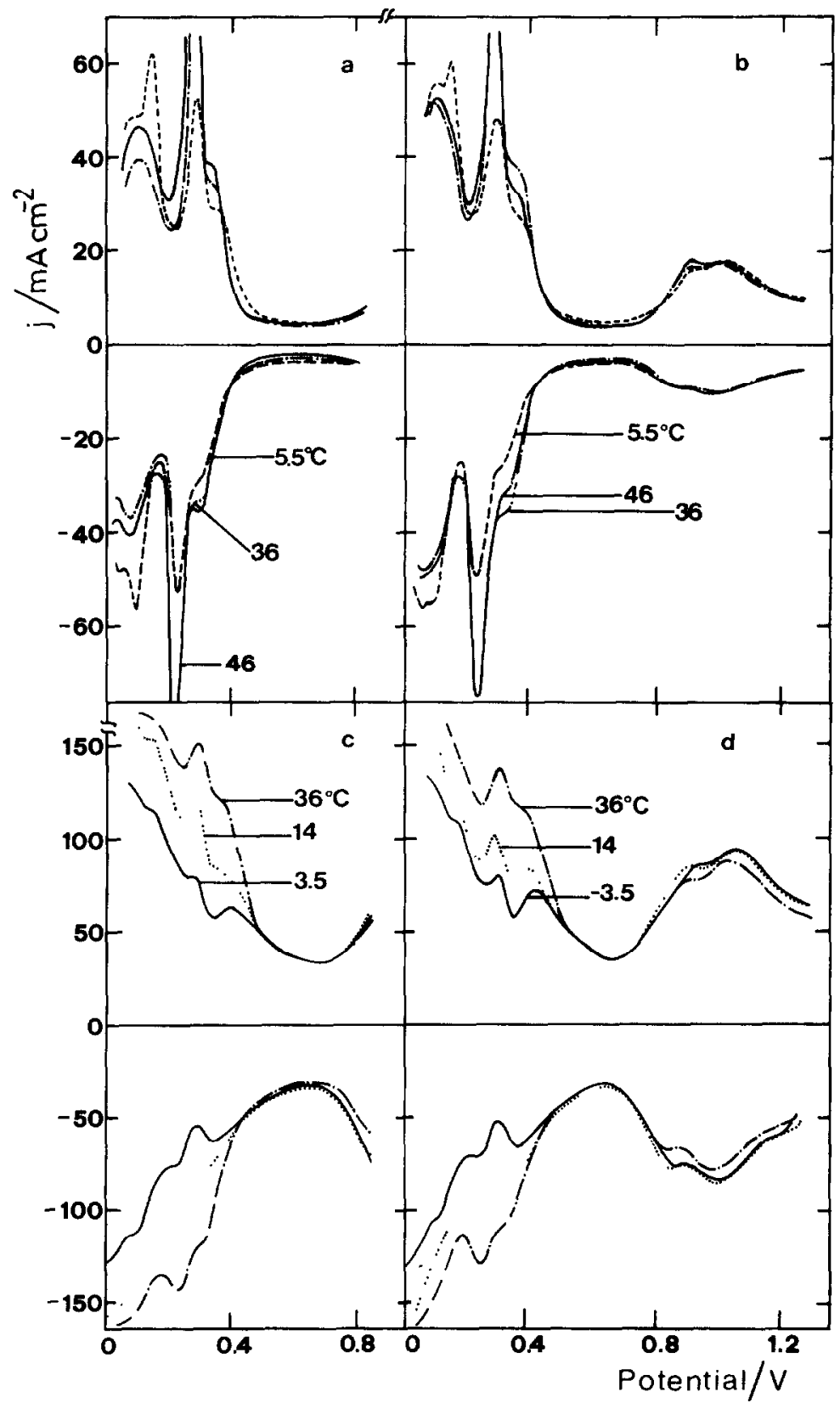

Fig. 5. TMTPS contours at different temperatures; $1 M \mathrm{H}_{2} \mathrm{SO}_{4}, v_{\mathrm{g}}=1 \mathrm{~V} / \mathrm{s}$. (a) HASE, $A_{\mathrm{m}}=60 \mathrm{mV}$, $v_{\mathrm{m}}=60 \mathrm{~V} / \mathrm{s}$; (b) OASE, $A_{\mathrm{m}}=60 \mathrm{~V} / \mathrm{s}, v_{\mathrm{m}}=60 \mathrm{~V} / \mathrm{s}$; (c) HASE, $A_{\mathrm{m}}=60 \mathrm{mV}, v_{\mathrm{m}}=600 \mathrm{~V} / \mathrm{s}$; (d) OASE, $A_{\mathrm{m}}=60 \mathrm{mV}, v_{\mathrm{m}}=600 \mathrm{~V} / \mathrm{s}$. 




Fig. 6. TMTPS contours at different temperatures; $0.5 M \mathrm{HClO}_{4}, v_{\mathrm{g}}=1 \mathrm{~V} / \mathrm{s}, v_{\mathrm{m}}=60 \mathrm{~V} / \mathrm{s}, A_{\mathrm{m}}=60 \mathrm{mV}$. $3.5^{\circ} \mathrm{C}(\cdots \cdots) ; 12^{\circ} \mathrm{C}(\cdot-\cdot-\cdot)$. (a) HASE; (b) OASE.

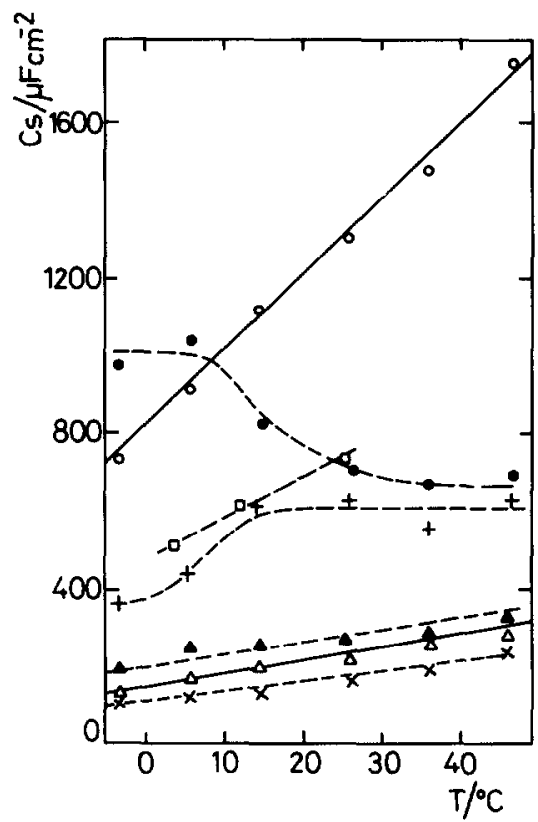

Fig. 7. Dependence of $C_{\mathrm{s}}$ on temperature for the three $\mathrm{H}$-adatom electrodesorption peaks. HASE, $A_{\mathrm{m}}=60 \mathrm{mV}, v_{\mathrm{g}}=1 \mathrm{~V} / \mathrm{s}$. (O) $1 M \mathrm{H}_{2} \mathrm{SO}_{4}$, peak $\mathrm{A}_{\mathrm{I}}, v_{\mathrm{m}}=60 \mathrm{~V} / \mathrm{s} ;(\Delta) 1 M \mathrm{H}_{2} \mathrm{SO}_{4}$, peak $\mathrm{A}_{\mathrm{I}}, v_{\mathrm{m}}=600$ $\mathrm{V} / \mathrm{s}$; (+) $1 M \mathrm{H}_{2} \mathrm{SO}_{4}$, peak $\mathrm{A}_{\mathrm{II}}, v_{\mathrm{m}}=60 \mathrm{~V} / \mathrm{s}$; (×) $1 M \mathrm{H}_{2} \mathrm{SO}_{4}$, peak $\mathrm{A}_{\mathrm{Il}}, v_{\mathrm{m}}=600 \mathrm{~V} / \mathrm{s}$; (O) $1 M$ $\mathrm{H}_{2} \mathrm{SO}_{4}$, peak $\mathrm{A}_{\mathrm{III}}, v_{\mathrm{m}}=60 \mathrm{~V} / \mathrm{s} ;(\Delta) 1 \mathrm{M} \mathrm{H}_{2} \mathrm{SO}_{4}$, peak $\mathrm{A}_{\mathrm{III}}, v_{\mathrm{m}}=600 \mathrm{~V} / \mathrm{s}$; (口) $0.5 \mathrm{MClO}_{4}$, peak $\mathrm{A}_{\mathrm{I}}$, $v_{\mathrm{m}}=60 \mathrm{~V} / \mathrm{s}$. 

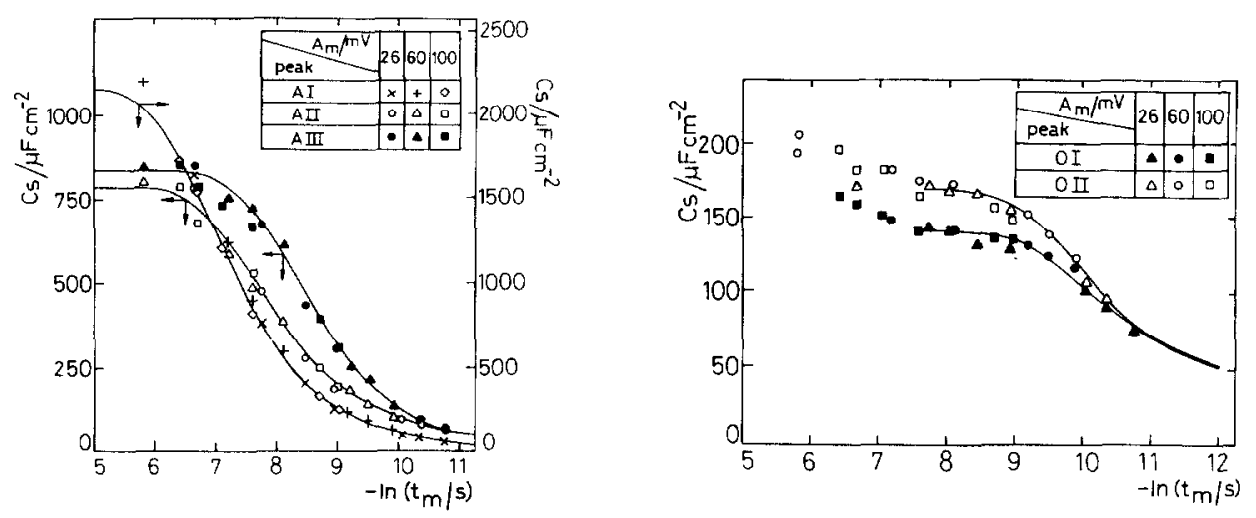

Fig. 8. Dependence of $C_{\mathrm{s}}$ on $t_{\mathrm{m}}$ at different $A_{\mathrm{m}}$ for the three $\mathrm{H}$-adatom electrodesorption peaks, HASE, $1 \mathrm{M} \mathrm{H}_{2} \mathrm{SO}_{4}, 25^{\circ} \mathrm{C}$. Full lines fit eqn. (1) with the parameters assembled in Table 1. Peak $\mathrm{A}_{\mathrm{I}}, A_{\mathrm{m}}=(\times)$ $26 \mathrm{mV}$; (+) $60 \mathrm{mV},(\diamond) 100 \mathrm{mV}$; peak $A_{I I}, A_{\mathrm{m}}=(O) 26 \mathrm{mV},(\Delta) 60 \mathrm{mV}$, (口) $100 \mathrm{mV}$; peak $\mathrm{A}_{\mathrm{III}}$,

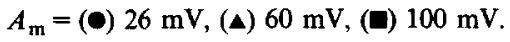

Fig. 9. Dependence of $C_{\mathrm{s}}$ on $t_{\mathrm{m}}$ at different $A_{\mathrm{m}}$ for $\mathrm{OH}$ electrodesorption, OASE, $1 \mathrm{M} \mathrm{H}_{2} \mathrm{SO}_{4} .25^{\circ} \mathrm{C}$. Full lines fit eqn. (1) with the parameters assembled in Table 1 . Peak $\mathrm{O}_{1}, A_{\mathrm{m}}=$ (৯) $26 \mathrm{mV}$, (•) $60 \mathrm{mV}$, (D) $100 \mathrm{mV}$; Peak $\mathrm{O}_{\mathrm{II}}, A_{\mathrm{m}}=(\Delta) 26 \mathrm{mV},(\mathrm{O}) 60 \mathrm{mV}$, (ㅁ) $100 \mathrm{mV}$

obtained for OASE. $C_{\mathrm{s}}$ vs. $t_{\mathrm{m}}$ plots for the double peak related to $\mathrm{OH}$ electrodesorption for OASE in $1 \mathrm{M} \mathrm{H}_{2} \mathrm{SO}_{4}$ are shown in Fig. 9 for different $A_{\mathrm{m}}$ values.

The experimental $C_{\mathrm{s}}$ vs. $t_{\mathrm{m}}$ data fit the following equation:

$C_{\mathrm{s}}=C_{\infty}+\left(C_{0}-C_{\infty}\right)\left(1-\mathrm{e}^{-t_{\mathrm{m}} / \tau}\right)$

where $C_{0}=\lim C_{\mathrm{s}}$ for $t_{\mathrm{m}} \rightarrow \infty\left(f_{\mathrm{m}} \rightarrow 0\right)$, and $C_{\infty}=\lim C_{\mathrm{s}}$ for $t_{\mathrm{m}} \rightarrow 0\left(f_{\mathrm{m}} \rightarrow \infty\right)$. Thus, $C_{\infty}$ represents the frequency-independent double layer capacitance, $C_{\mathrm{dl}}$, and $C_{0}$ is the total capacitance at low frequency. The values of $C_{0}, C_{\infty}$ and $\tau$ were obtained from conventional iterative numerical calculation for peaks $A_{I}, A_{I I}, A_{I I I}$, $\mathrm{O}_{\mathrm{I}}$ and $\mathrm{O}_{\mathrm{II}}$ in $1 \mathrm{M} \mathrm{H}_{2} \mathrm{SO}_{4}$ and for peaks $\mathrm{A}_{\mathrm{I}}$ and $\mathrm{A}_{\mathrm{III}}$ in $0.5 M \mathrm{HClO}_{4}$ (Table 1). The value of $\tau$ from peaks $\mathrm{A}_{\mathrm{I}}, \mathrm{A}_{\mathrm{II}}$ and $\mathrm{A}_{\mathrm{III}}$ increase in the order $\tau\left(\mathrm{A}_{\mathrm{III}}\right)<\tau\left(\mathrm{A}_{\mathrm{II}}\right)<$ $\tau\left(A_{I}\right)$, whereas for both peaks $O_{I}$ and $O_{I I}$ the value of $\tau$ is about $10^{-5} \mathrm{~s}$. From these results it can be concluded that the rate of the $\mathrm{OH}$ electroadsorption/electrodesorption is about one order of magnitude faster than the rate of the corresponding $\mathrm{H}$-adatom reactions.

The dependence of $C_{\mathrm{s}}$ on temperature involves $C_{\infty}, C_{0}$ and $\tau$. At constant $t_{\mathrm{m}}$, on the assumption that $C_{\mathrm{dl}}$ is independent of temperature and that $C_{0}$ increases linearly with temperature, as was found for peaks $A_{I} / C_{I}$ in pc Pt electrodes [17], one can estimate the activation energy $\Delta E^{*}$ from the Arrhenius-type equation:

$1 / \tau=A \exp \left(-\Delta E^{*} / R T\right)$

where $A$ is the pre-exponential factor.

From the dependence of $C_{\mathrm{s}}$ for the peaks $\mathrm{A}_{1} / \mathrm{C}_{1}$ on temperature for either $t_{\mathrm{m}}=10^{-3} \mathrm{~s}$ or $t_{\mathrm{m}}=10^{-4} \mathrm{~s}, A=4 \times 10^{5} \mathrm{~s}^{-1}$ and $\Delta E^{*}=15.1 \mathrm{~kJ} / \mathrm{mul}$. 
TABLE 1

Kinetic data derived from TMTSV for $\mathrm{H}$-adatom electrodesorption in $1 \mathrm{M} \mathrm{H}_{2} \mathrm{SO}_{4}$ and $0.5 \mathrm{M} \mathrm{HClO}$ and for $\mathrm{OH}$-adatom electrodesorption in $1 \mathrm{M} \mathrm{H}_{2} \mathrm{SO}_{4}$ at $25^{\circ} \mathrm{C}$

\begin{tabular}{lccl}
\hline Peak & $C_{0} / \mu \mathrm{F} \mathrm{cm}^{-2}$ & $C_{\infty} / \mu \mathrm{F} \mathrm{cm}^{-2}$ & $\tau / \mathrm{s}$ \\
\hline$I M \mathrm{H}_{2} \mathrm{SO}_{4}$ & $2157 \pm 25$ & $10 \pm 0.4$ & $(1 \pm 0.2) \times 10^{-3}$ \\
$\mathrm{~A}_{\mathrm{I}}$ & $782 \pm 8$ & $29 \pm 1$ & $(5 \pm 0.5) \times 10^{-4}$ \\
$\mathrm{~A}_{\mathrm{II}}$ & $827 \pm 8$ & $4 \pm 0.4$ & $(2.6 \pm 0.5) \times 10^{-4}$ \\
$\mathrm{~A}_{\mathrm{III}}$ & $139 \pm 1$ & $36 \pm 1$ & $(4.3 \pm 0.6) \times 10^{-5}$ \\
$\mathrm{O}_{\mathrm{I}}$ & $166 \pm 2$ & $36 \pm 1$ & $(5.0 \pm 0.6) \times 10^{-5}$ \\
$\mathrm{O}_{\text {II }}$ & & & \\
$0.5 \mathrm{MHClO}$ & $1381 \pm 15$ & $8 \pm 0.4$ & $(1.4 \pm 0.2) \times 10^{-3}$ \\
$\mathrm{~A}_{\mathrm{I}}$ & $773 \pm 7$ & $4 \pm 0.4$ & $(5.9 \pm 0.5) \times 10^{-4}$ \\
$\mathrm{~A}_{\text {III }}$ & & & \\
\hline
\end{tabular}

\section{DISCUSSION}

The faceted (100) Pt surfaces denoted as HASE and OASE exhibit different voltammetric characteristics for $\mathrm{H}$-adatom and $\mathrm{OH}$ electroadsorption/electrodesorption reactions depending on the frequency of the modulating signal, electrolyte composition and temperature.

In principle, the different relaxation times for the $\mathbf{H}$-adatom electroadsorption (Table 1) indicate a change in the kinetics of the reactions taking place in the potential ranges of each pair of peaks. These kinetic differences can be attributed either to a change in the value of the specific rate constant for each reaction, particularly through a change in the corresponding activation energy, or to a different surface concentration of the specific reactants, or to different structures of the electrode/solution interface prevailing within the potential range of each pair of conjugated current peaks, implying different $\mathrm{Pt}$ reacting atoms at the surface, $\mathrm{H}$-adatoms adsorbed at different sites, distinct structures of adsorbed water, etc.

Let us assume that each pair of peaks defined in the TMTPS voltammetric envelope corresponds to the electroadsorption/electrodesorption of energetically distinguishable $\mathrm{H}$-adatoms, and that the frequency response of each species can be followed through the corresponding $C_{\mathrm{s}}$ value. The simplest theory for a single quasi-reversible electron transfer step such as:

$\mathrm{Pt}(\mathrm{H})_{\mathrm{ad}}+\mathrm{H}_{2} \mathrm{O}=\mathrm{Pt}+\mathrm{H}_{3} \mathrm{O}^{+}+e^{-}$

where competitive adsorption is neglected, establishes that $C_{\mathrm{s}}$ as determined from single sweep linear voltammetry, should be frequency independent [18]. In the present case this situation is reached only for $f_{\mathrm{m}} \rightarrow 0\left(t_{\mathrm{m}} \rightarrow \infty\right)$.

An alternative and perhaps more reasonable approach for explaining the $C_{\mathrm{s}}$ vs. $f_{\mathrm{m}}$ dependence is to assume that the degree of surface coverage by $\mathrm{H}$-adatoms is determined by a frequency-dependent competitive adsorption of $\mathrm{H}$-atoms $\left(\theta_{\mathrm{H}}\right)$, water molecules $\left(\theta_{\mathrm{w}}\right)$ and anions $\left(\theta_{\mathrm{a}}\right)$ for particular sites on the electrode surface. 
Then, at any potential the total degree of surface coverage $\left(\theta_{T}\right)$ under non-steady conditions at $f_{\mathrm{m}}$, can be expressed as the sum of at least three contributions, namely:

$\boldsymbol{\theta}_{\mathrm{T}}\left(f_{\mathrm{m}}\right)=\boldsymbol{\theta}_{\mathrm{H}}\left(f_{\mathrm{m}}\right)+\boldsymbol{\theta}_{\mathrm{w}}\left(f_{\mathrm{m}}\right)+\boldsymbol{\theta}_{\mathrm{a}}\left(f_{\mathrm{m}}\right)$

Now, let us assume formally that the $\mathrm{H}$-electrodesorption reaction proceeds through a consecutive mechanism consisting of a series of chemical steps represented as follows:

$$
\begin{aligned}
& {\left[\mathrm{Pt}(\mathrm{H}) \ldots \mathrm{H}_{2} \mathrm{O}\right]_{1} \rightleftarrows\left[\mathrm{Pt}(\mathrm{H}) \ldots \mathrm{H}_{2} \mathrm{O}\right]_{2} \rightleftarrows \ldots \rightleftarrows\left[\mathrm{Pt}(\mathrm{H}) \ldots \mathrm{H}_{2} \mathrm{O}\right]_{N}} \\
& {\left[\mathrm{Pt}(\mathrm{H}) \ldots \mathrm{H}_{2} \mathrm{O}\right]_{N} \rightleftarrows \mathrm{Pt}+\mathrm{H}_{3} \mathrm{O}^{+}+e^{-}}
\end{aligned}
$$

where the brackets with subscripts $1,2, \ldots, N$ in eqn. (5) denote different ensembles of $\mathrm{H}$-adatoms in distinguishable sites $(1,2, \ldots, N)$ interacting with surrounding water molecules and ions. According to reaction (6) the electrooxidation process requires the location of a $\mathrm{H}$-adatom at site $N$. The surface mobility of $\mathrm{H}$-adatoms through the series of reactions indicated in eqn. (5) should imply the reaccommodation of surrounding water molecules and ions. Reaction (5) should involve a practically instantaneous surface equilibration among the different adsorption sites as recently proposed for the multisite mechanism of $\mathbf{H}$ adsorption on $\mathrm{Pt}$ in acid solutions $[13,19]$.

For first-order reaction (5) becoming the rds, the degree of surface coverage by $\mathrm{H}$-adatoms, $\theta_{\mathrm{H}, N}$, at site $N$ at $t=t_{\mathrm{m}}$, is given by:

$\boldsymbol{\theta}_{\mathrm{H}, N}\left(t_{\mathrm{m}}\right)=\boldsymbol{\theta}_{\mathrm{H}, 1}\left[1-\exp \left(-k_{1} t_{\mathrm{m}}\right)\right]$

$k_{1}$ is an apparent rate constant which depends on both the electrode site and electrolyte composition.

The experimental value of $C_{\mathrm{s}}$ can be expressed, in principle, as the sum of two terms

$C_{\mathrm{s}}=C_{\mathrm{dl}}+C_{\mathrm{ad}}$

where $C_{\mathrm{dl}}$ is the double layer capacitance and $C_{\mathrm{ad}}$ is the adsorption pseudo-capacitance. Provided that, within the potential range covered by the amplitude $A_{\mathrm{m}}$ of the modulating cycle, $\theta_{\mathrm{H}, 1}$ remains practically constant, the dependence of $C_{\mathrm{ad}}$ on $t_{\mathrm{m}}$ is derived from the dependence of $\theta_{\mathrm{H}, N}$ on $t_{\mathrm{m}}$ through eqn. (7). As the coverage by $\theta_{\mathrm{H}, N}$ is small independently of $\theta_{\mathrm{T}}$, and assuming then that a Langmuir isotherm is obeyed, one obtains:

$$
C_{\mathrm{ad}}\left(t_{\mathrm{m}}\right)=-q_{\mathrm{m}} \frac{\mathrm{d} \theta_{\mathrm{H}, N}}{\mathrm{~d} E}=\frac{q_{\mathrm{M}} F}{R T} \theta_{\mathrm{H}, N}\left(t_{\mathrm{m}}\right)\left[\frac{1-\theta_{\mathrm{H}, N}\left(t_{\mathrm{m}}\right)-\sum_{i=1}^{N-1} \theta_{t}}{1-\sum_{t=1}^{N-1} \theta_{t}}\right]
$$


where $q_{\mathrm{M}}$ is the monolayer charge density and $\Sigma \theta_{1}$ accounts for the contributions of the 1 to $N-1$ adsorbed ensembles. Then, after substituting eqn. (7) into eqn. (9) one obtains:

$C_{\mathrm{s}}=C_{\mathrm{dl}}+\frac{q_{\mathrm{M}} F}{R T} \theta_{\mathrm{H}, 1}\left[1-\exp \left(-k_{1} t_{\mathrm{m}}\right)\right]\left[\frac{1-\theta_{\mathrm{H}, 1}+\theta_{\mathrm{H}, 1} \exp \left(-k_{1} t_{\mathrm{m}}\right)-\sum_{i=1}^{N-1} \theta_{i}}{1-\sum_{i=1}^{N-1} \theta_{t}}\right]$

Equation (10) implies two limiting situations. For $t_{\mathrm{m}}=0$ :

$C_{\mathrm{s}}\left(t_{\mathrm{m}}=0\right)=C_{\mathrm{dl}}$

and for $t_{\mathrm{m}} \rightarrow \infty$ :

$C_{\mathrm{s}}\left(t_{\mathrm{m}} \rightarrow \infty\right)=C_{\mathrm{d} !}+\frac{q_{\mathrm{M}} F}{R T} \theta_{\mathrm{H}, 1}\left[\frac{1-\theta_{\mathrm{H}, 1}-\sum_{i=1}^{N-1} \theta_{1}}{1-\sum_{i=1}^{N-1} \theta_{i}}\right]$

Therefore, the term $C_{\mathrm{s}}\left(t_{\mathrm{m}} \rightarrow \infty\right)$ becomes equivalent to $\left(C_{0}-C_{\infty}\right)$ in eqn. (1). Then, by introducing eqn. (12) into eqn. (10) one obtains:

$$
\begin{aligned}
C_{\mathrm{s}}= & C_{\mathrm{d} 1}+\left\{\left(C_{\mathrm{s}}\left(t_{\mathrm{m}} \rightarrow \infty\right)-C_{\mathrm{dl}}\right)\left[1-\exp \left(-k_{1} t_{\mathrm{m}}\right)\right]\right. \\
& \left.+\frac{q_{\mathrm{M}} F}{R T} \theta_{\mathrm{H}, 1}^{2}\left[1-\exp \left(-k_{1} t_{\mathrm{m}}\right)\right] \exp \left(-k_{1} t_{\mathrm{m}}\right)\right\}
\end{aligned}
$$

where the second term in brackets can be disregarded. Hence, eqn. (13) results:

$C_{s}=C_{\mathrm{dl}}+\left\{\left(C_{s}\left(t_{\mathrm{m}} \rightarrow \infty\right)-C_{\mathrm{d} 1}\right)\left[1-\exp \left(-k_{1} t_{\mathrm{m}}\right)\right]\right\}$

Equation (14) is similar to eqn. (1) with $k_{1}=1 / \tau$. The values for the relaxation time constants reported in Table 1 in $1 \mathrm{M} \mathrm{H}_{2} \mathrm{SO}_{4}$, at $25^{\circ} \mathrm{C}$ are reasonably comparable to that reported recently from potential step relaxation data [13].

In the proposed reaction model the metal-H-adatom-anion-water ensemble can be regarded as a potential dependent structure at the different crystallographic planes where the influence of water structure presumably plays an outstanding role. On the other hand, the $\mathrm{H}$-adatom reactions on single crystal $\mathrm{Pt}$ in $0.5 \mathrm{M} \mathrm{H}_{2} \mathrm{SO}_{4}$ exhibit characteristic voltammetric pairs of peaks assigned to the different crystallographic planes [20-22]. The plausible role played by the structure of interfacial water for the $\mathbf{H}$-adatom reactions at the different planes is, in principle, in agreement with infrared spectroscopic data, from which it was concluded that weakly adsorbed $\mathrm{H}$-adatoms interact strongly with water [23,24]. Furthermore, various models developed for the metal/water interface and metal/electrolyte/solution interface conclude that the first layer of water behaves as a relatively rigid or 
highly viscous ice-like structure $[25,26]$. The probability of cluster formation involving a relatively large number of water molecules is also sustained by recent theoretical computations of liquid water structures at room temperature [27].

The $\mathrm{H}$-adatom reaction becomes more facile in the potential range of weakly adsorbed $\mathrm{H}$-adatoms (peaks $\mathrm{A}_{\mathrm{III}} / \mathrm{C}_{\mathrm{III}}$ ), where the influence of both the faceted (100) $\mathrm{Pt}$ structure and anion adsorption are minimal. The potential range of peaks $\mathrm{A}_{\mathrm{III}} / \mathrm{C}_{\mathrm{III}}$ is probably more negative than the potential of zero charge, $E_{\mathrm{pzc}}$, so that the value of $\theta_{\mathrm{a}}\left(t_{\mathrm{m}}\right)$ presumably approaches zero, and $\theta_{\mathrm{w}}\left(t_{\mathrm{m}}\right)$ should be frequency independent in a predominantly cluster-like structure [28]. So the value of $\theta_{\mathrm{T}}$ appears to be determined principally by the capability of the $\mathrm{H}$-adatom reaction to follow the modulating frequency through the water cluster structure. In this respect it should be noticed that the relaxation time from peaks $\mathrm{A}_{\mathrm{III}} / \mathrm{C}_{\mathrm{III}}$ is in reasonable agreement with that of polycrystalline ice obtained by extrapolation to $298 \mathrm{~K}$ from experimental data on the frequency dispersion of the dielectric constant of ice [29]. Peaks $\mathrm{A}_{\mathrm{III}} / \mathrm{C}_{\mathrm{III}}$ appearing both in $1 \mathrm{M} \mathrm{H}_{2} \mathrm{SO}_{4}$ and $0.5 M \mathrm{HClO}_{4}$ are probably also influenced by residual crystallographic planes other than (100) planes remaining from the original pc Pt.

The $\mathrm{H}$-adatom reaction taking place at the potential window of peaks $A_{I} / C_{I}$ exhibits the slowest kinetic behaviour, the greatest temperature effect and is influenced predominantly by the preferred orientation of the electrode surface. At this potential window the sum of $\theta_{\mathrm{a}}+\theta_{\mathrm{w}}$ in eqn. (4) can be assumed as a term depending principally on the structure of the electrolyte solution. In this case, the specific adsorption of anions probably induces an energy leveling of reacting sites at the metal surface, since the greater is the anion adsorbability, the sharper are the current peaks.

The $\mathrm{H}$-adatom reaction in the potential range of peaks $\mathrm{A}_{\mathrm{II}} / \mathrm{C}_{\mathrm{II}}$ appears as fast as in the potential range of peaks $A_{I I I} / C_{I I I}$, although peaks $A_{I I} / C_{I I}$ also show the influence of the characteristics of the electrode surface, namely, the proper (100) crystallographic planes or kink sites [6,30]. In the potential range of peaks $A_{11} / C_{11}$ the voltammetric difference between $1 \mathrm{M} \mathrm{H}_{2} \mathrm{SO}_{4}$ and $0.5 \mathrm{M} \mathrm{HClO}_{4}$ can be explained qualitatively on the assumption that $\theta_{\mathrm{T}}$ depends mainly on $\theta_{\mathrm{a}}$, which in turn depends on the corresponding non-steady, presumably $f_{\mathrm{m}}$-independent adsorption isotherm. In this case anion adsorption would tend to accelerate the H-electrosorption reaction by stabilizing electrostatically a partial charge transition state, as suggested by Frumkin [31].

Influence of the anion in modifying the structure of the solvent was concluded from the properties of the electrolyte solutions [32] and in this respect Samoilov's approach to this problem appears particularly useful at the level of the electrode/solution interface [33]. Accordingly, in water a distinction can be made between small and large ions and $\mathrm{H}$-bond forming and non-H-bond forming ions. Furthermore, if the anion-electrode interactions change with the potential (charge) on the electrode, it is not surprising that the structure at the solution side of the electrode/solution interface becomes potential dependent [34].

From the discussion of the kinetics of the three $\mathrm{H}$-adatom reactions one can 
conclude that there is a cooperative effect of surface structure-sensitive and solution structure-sensitive contributions at the reacting ensemble represented by eqn. (5). It is plausible that the kinetics of the process be determined by the capability of water molecules within the ensemble to follow the configurational changes implied by the electrochemical process. Therefore, at relatively large values of $f_{\mathrm{m}}$ the overall reaction is inhibited. This conceptual approach of the electrochemical reaction is, in principle, predicted in Marcus's theory for charge transfer [35], except that the relaxation times are higher than those expected in homogeneous systems because of the "quasi-frozen" state of the solvent at the reacting ensembles. The foregoing interpretation is sustained further by the influence of temperature on the TMTSV. The dependence of $C_{\mathrm{s}}$ on temperature for peaks $\mathrm{A}_{\mathrm{II}} / \mathrm{C}_{\mathrm{II}}$ and $\mathrm{A}_{\mathrm{III}} / \mathrm{C}_{\mathrm{III}}$ becomes less remarkable than for peaks $A_{I} / C_{I}$ (Fig. 6) and this effect can be associated with the relatively greater influence of the solution structure-sensitive contribution in the neighbourhood of $E_{\mathrm{pzc}}$.

A multiplicity of TMTSV peaks is also obtained in the potential range of the reversible $\mathrm{OH}$-adsorbed reaction, although these results are to some extent obscured by both the increasing interference of anion adsorption and the possible influence of surface reconstruction. As already established for noble metal electrodes in acids [36-38], the presence of $\mathrm{HSO}_{4}^{-}$ions, which are adsorbed more strongly than $\mathrm{ClO}_{4}^{-}$ ions. shifts the threshold potential of the electrochemical reactions appreciably towards more positive potentials. Likewise, the appearance of a hump in the double layer region in $0.5 \mathrm{M} \mathrm{HClO}_{4}$ suggests only that the constant double layer capacitance region in $1 \mathrm{M} \mathrm{H}_{2} \mathrm{SO}_{4}$ is due principally to the anion-electrode interaction. Therefore, at sufficiently positive potentials the underpotential decomposition of water yields $\mathrm{OH}$-electroadsorbed species and $\mathrm{HSO}_{4}^{-}$ion desorption, according to the formal reaction:

$\mathrm{Pt}_{i}\left(\mathrm{HSO}_{4}^{-}\right)+\mathrm{H}_{2} \mathrm{O}=\mathrm{Pt}_{i}(\mathrm{OH})+\mathrm{H}^{+}+\mathrm{HSO}_{4}^{-}+e^{-}$

The two relaxation times obtained for the $\mathrm{OH}$-adsorbed reactions are one order of magnitude smaller, namely, the corresponding reaction rates are greater than those corresponding to the $\mathrm{H}$-adatom reactions. This kinetic difference can be taken as an indication that as the potential is increased progressively, the positive charge on the metal induces the gradually breaking ice-like structures and favours a greater orientation of dipole water molecules which presumably enhances the rate of reaction (16).

\section{ACKNOWLEDGEMENT}

This research project is supported financially by the Universidad Nacional de La Plata, the Consejo Nacional de Investigaciones Científicas y Téchnicas and the Comisión de Investigaciones Científicas de la Provincia de Buenos Aires. 


\section{REFERENCES}

1 R.M. Cerviño, W.E. Triaca and A.J. Arvia, J. Electrochem. Soc., 132 (1985) 266; J. Electroanal. Chem., 182 (1985) 51.

2 J.C. Canullo, W.E. Triaca and A.J. Arvia, J. Electroanal. Chem., 175 (1984) 337.

3 R.M. Cerviño, A.J. Arvia and W. Vielstich, Surf. Sci., 154 (1985) 623.

4 W.E. Triaca, T. Kessler, J.C. Canullo and A.J. Arvia, J. Electrochem. Soc., 134 (1987) 1165.

5 J. Gómez, L. Vázquez, A.M. Baró, N. García, C.L. Perdriel, W.E. Triaca and A.J. Arvia, Nature London), 323 (1986) 612.

6 J. Gomez, L. Vazquez, A.M. Baró, N. Garcia and A.J. Arvia, Surf. Sci., 181 (1987) 98.

7 S.A. Bilmes, M.C. Giordano and A.J. Arvia, Electrochemical Society Meeting, Toronto, May 12-17, 1985, Extended Abstracts, Vol. 85-1, The Electrochemical Society, Pennington, NJ, p. 918.

8 B.E. Conway, H. Angerstein-Kozlowska, F.C. Ho, J. Klinger, B. Mac Dougall and S. Gottesfeld, Discuss. Faraday Soc., 56 (1973) 210.

9 N.R. de Tacconi, J.O. Zerbino and A.J. Arvia, J. Electroanal. Chem., 79 (1977) 287.

10 S.A. Bilmes and A.J. Arvia, J. Electroanal. Chem., 198 (1986) 137.

11 T. Ohsaka, Y. Sawada, T. Yoshida and K. Nihei, J. Electrochem. Soc., 123 (1976) 1339.

12 S.M. Glarum and J.M. Marshall, J. Electrochem. Soc., 126 (1979) 424.

13 F.E. Woodard and C.N. Reilley, J. Electroanal. Chem., 167 (1984) 65.

14 B.E. Conway, H. Angerstein-Kozlowska, W.B. Sharp and E.E. Criddle, Anal. Chem., 45 (1973) 1331.

15 H. Angerstein-Kozlowska, B.E. Conway, B. Barnett and J. Mozota, J. Electroanal. Chem., 100 (1979) 417.

16 B.E. Conway, H. Angerstein-Kozlowska and W.B.A. Sharp, J. Chem. Soc. Faraday Trans. 1, 74 (1978) 1373.

17 A. Fernández Anta, S.A. Bilmes, M.C. Giordano and A.J. Arvia, 5th Physical Chemistry Congress, Mar del Plata, Argentina, April 1987.

18 S. Srinivasan and E. Gileadi, Electrochim. Acta, 11 (1966) 321.

19 E. Yeager in J.D.E. McIntyre, S. Srinivasan and F.G. Will (Eds.), Proc. Symp. Electrode Materials and Energy Conversion, The Electrochemical Society, Princeton, 1977, p. 149.

20 J. Clavilier, J. Electroanal. Chem., 107 (1980) 211; J. Clavilier and D. Armand, J. Electroanal. Chem., 199 (1986) 187.

21 F.E. Wondward, C.L. Scortichini and C.N. Reilley, I. Electroanal. Chem., 151 (1983) 109.

22 F.T. Wagner and P.N. Ross, J. Electroanal. Chem., 150 (1983) 141.

23 A. Bewick, K. Kunimatsu, J. Robinson and J.W. Russell, J. Electroanal. Chem., 119 (1981) 175.

24 A. Bewick and J. Russell, J. Electroanal. Chem., 132 (1982) 329.

25 W.B. Eversole and P.H. Lahr, J. Chem. Phys., 9 (1941) 530.

26 S. Trasatti, Electrochim. Acta, 28 (1983) 1083; Mater. Chem. Phys., 12 (1985) 507.

27 E. Clementi, J. Phys. Chem., 89 (1985) 4426.

28 P.J. Hyde, C.J. Maggiore, A. Redondo, S. Srinivasan and S. Gottesfeld, J. Electroanal. Chem., 186 (1985) 267.

29 R.P. Anti and R.H. Cole, J. Chem. Phys., 20 (1952) 1309.

30 C.L. Scortichini and C.N. Reilley, J. Electroanal. Chem., 139 (1982) 233.

31 A.N. Frumkin in P. Delahay (Ed.), Advances in Electrochemistry and Electrochemical Engineering, Vol. 3, Interscience, New York, 1963, p. 287.

32 A.K. Lyashchenko, J. Res. Inst. Catalysis, Hokkaido Univ., 25 (1977) 129.

33 O.Ya. Samoilov in R.A. Horne (Ed.), Water and Aqueous Solutions, Wiley-Interscience, New York, 1972.

34 S. Trasatti, J. Electroanal. Chem., 150 (1983) 1.

35 R.A. Marcus, J. Chem. Phys., 43 (1965) 679.

36 J.C. Huang, W.E. O'Grady and E. Yeager, J. Electrochem. Soc., 124 (1977) 1733.

37 R.O. Lezna, N.R. de Tacconi and A.J. Arvia, J. Electrochem. Soc., 126 (1979) 2140.

38 W. Visscher and M.A.V. Devanathan, J. Electroanal. Chem., 8 (1964) 127. 